\title{
CHRONIC TENSION-TYPE HEADACHE: MUSCLE OVERACTIVITY VERSUS DEFICIENT PAIN CONTROLS
}

\author{
BHAWNA MATTOO ${ }^{1}$, SUMAN TANWAR ${ }^{1}$, ROHIT BHATIA ${ }^{2}$, MANJARI TRIPATHI ${ }^{2}$, RENU BHATIA ${ }^{1 *}$ \\ ${ }^{1}$ Department of Physiology, All India Institute of Medical Sciences, New Delhi - 110 029, India. ${ }^{2}$ Department of Neurology, All India \\ Institute of Medical Sciences, New Delhi - 110 029, India. Email: renuaiims28@gmail.com
}

Received: 26 December 2017, Revised and Accepted: 23 April 2018

\section{ABSTRACT}

Objective: The oscillating school of thought between the peripheral and central mechanisms of pain origin hinders the selection of appropriate therapy for chronic tension-type headache (CTTH). The aim of this study was to assess the role of central and peripheral pain mechanisms together in CTTH.

Methods: In the present study, we compared surface electromyography (sEMG) amplitudes and nociceptive flexion thresholds in patients diagnosed with CTTH $(n=30)$ with age-matched healthy controls $(n=30)$. For central pain modulation with spinal and supraspinal influences on nociception, we recorded nociceptive flexion reflex (NFR) by stimulating the sural nerve and observing the biceps femoris muscle response. sEMG was done for the temporalis and trapezius muscles at rest, during mental activity and during maximum voluntary contraction to assess contribution from peripheral pain.

Results: We observed a decreased NFR threshold in CTTH patients as compared to healthy controls, suggesting a hyperalgesic state due to central factors. Electromyographic activity of trapezius muscle was increased at rest in CTTH while both temporalis and trapezius showed an overactivity in patients during mental task.

Conclusion: Central factors are important in the pathogenesis of CTTH while, peripheral factors, such as stress-related muscle spasm may also contribute to pain state.

Keywords: Central sensitization, Peripheral sensitization, Nociceptive flexion reflex, Electromyography.

(C) 2018 The Authors. Published by Innovare Academic Sciences Pvt Ltd. This is an open access article under the CC BY license (http://creativecommons. org/licenses/by/4. 0/) DOI: http://dx.doi.org/10.22159/ajpcr.2018.v11i8.24433

\section{INTRODUCTION}

Tension-type headache despite being the most prevalent primary headache, has not received the attention it deserves due to an unclear etiopathogenesis. The controversial role of peripheral and central pain mechanism exists [1], making it difficult to target appropriate system (peripheral muscles or central pain pathway) for therapy [2], leading to unnecessary self-medication in patients [3]. Earlier, the tensiontype headache was thought to be a purely muscular headache derived from overactivity of the pericranial muscles [4]. The muscles generally concerned were the pericranial and cervical muscles, with many reports suggesting the role of the trapezius muscle. However, these reports were inconsistent in terms of the muscle testing paradigms. We attempt to understand the role of two most frequently implicated muscles; trapezius and temporalis during rest, mental activity, and maximum voluntary contraction (MVC). Central sensitization could be the second side to this chronic debilitating headache, which is reflected by increased pain sensitivity reported with the disease. Nociceptive flexion reflex (NFR) which is an objective measure of pain and a reliable index of spinal pain modulation, may unmask the role of central pain modulation in chronic tension-type headache (CTTH) patients [5]. Therefore, both surface electromyography (sEMG) and NFR are reliable methods to look at peripheral and central pain modulation.

Our study is novel because it looks these parameters together in patients diagnosed with CTTH and compares with healthy controls, providing an insight into the pain mechanisms involved.

\section{METHODS}

This was a case-control study involving 330 patients with CTTH and30 healthy controls were recruited from from May 2015 to August
2016 after obtaining ethical clearance from the Institutional Ethical Committee. Both male and female CTTH patients, aged between 18 and 55 years, were enrolled from Neurology Outpatient Department. Headache diagnosis was based on the International Classification of Headache Disorders- 3 beta [6]. Detailed history was taken, and patients asked to rate their pain on a scale of 1-10, ranging from no pain to worst imaginable pain (Numerical Rating Scale).

\section{NFR recording}

To measure the NFR threshold, the electro-cutaneous stimulation and sEMG recording sites were prepared and the electrodes placed. The recording was done $18^{\text {th }}$ and $23^{\text {rd }}$ day of menstrual cycle (mid-luteal phase) between 8 and 11 a.m. after an overnight fast. Patients were asked to lie comfortably in supine position for 15-20 min after which, their knee was flexed at $130^{\circ}$, and the ankle flexed at $90^{\circ}$ on the couch. Two Ag-AgCl cup electrodes were used to stimulate the sural nerve at the retromalleolar area. The interelectrode distance was kept at $30 \mathrm{~mm}$. Pre-gelled disposable Ag-AgCl disc electrodes (Nikomed, USA) were utilized to record sEMG from the short head of biceps femoris muscle. The ground was placed over the patella on the ipsilateral side. Electrical stimuli to the sural nerve were delivered in trains of five rectangular wave pulses of $1 \mathrm{~ms}$ duration at a frequency of $200 \mathrm{~Hz}$ with B.S.L. STMA, Biopac Systems, Inc. Santa Barbara, California [7,8]. To avoid stimulus habituation, the trains were delivered randomly every 5-15 s. The intensity of stimulation eliciting a response at a rate of 60$90 \%$ in a series of approximately 20 stimuli was considered the NFR threshold [5]. The stimulation was initiated from $10 \mathrm{~V}$ and increased in steps of $5 \mathrm{~V}$ until the response was recorded in the EMG tracing. The stimulus intensity was then reduced in steps of $1 \mathrm{~V}$ until the reflex disappeared. The NFR threshold was defined as the average of the voltage, which produced reflex during the ascending sequence and the 
voltage below which the reflex could no longer be generated during the descending sequence.

\section{EMG recording}

Pairs of Ag-AgCl pre-gelled electrodes (Nikomed, USA) of diameter $1 \mathrm{~cm}$ were used to record SEMG from temporalis and upper trapezius muscle. The was cleaned and gently abraded. For temporalis, one electrode was placed $10 \mathrm{~mm}$ lateral to the external angle of the orbit and other directly above the first, the reference was placed over the the frontal bone. For the upper trapezius, electrodes were centered midway between the C7 and acromion [9]. EMG signals were recorded on Biopac Student Lab V 3.6.2 (B.S.L) system, bandpass filtered (30-250 Hz) and sampled at $1000 \mathrm{~Hz}$. The recording was done at rest, during mental activity (subjects were asked to subtract 7 serially from 100) and with maximum voluntary contraction, where subjects were asked to clench their teeth or shrug their shoulders forcefully for the activation of temporalis and trapezius, respectively [10]. The EMG was analyzed offline using B.S.L ${ }^{\circledR}$ software. Alternate bins of $10 \mathrm{~s}$ analyzed excluding the first and the last $10 \mathrm{~s}$, and peak to peak amplitude (in microvolts $[\mu \mathrm{V}]$ ) was measured for the three conditions. For MVC, the area under the curve (AUC) (in $\mu V$-s) and time to fatigue onset (in seconds) was taken as a surrogate for fatigability.

\section{Statistical analysis}

Results are presented as median with quartiles for nonparametric and as mean \pm standard deviation for parametric data. Statistical significance between control and CTTH group compared using unpaired t-test after checking for normality with D'Agostino and Pearson omnibus normality test. All analyses were done on GraphPad Prism v 5.0.

\section{RESULTS}

General characteristics of patients and controls are depicted Table 1.

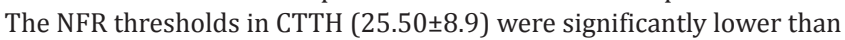
controls $(33.75 \pm 10.5), p=0.009$. There was no significant difference in other NFR parameters such as latency, amplitude, and duration (Table 2).

sEMG amplitude at rest showed no significant difference in the amplitude $(\mu \mathrm{V})$ of temporalis between CTTH patients and controls. While there was bilateral over activity at rest of the trapezius muscle in CTTH patients, which was statistically significant $(p=0.001)$ in the right trapezius $62(32,148)$ compared to healthy controls $27(20,39)$ (Table 3).

sEMG during mental activity showed that there was significant $(p=0.0013)$ overactivity of the right temporalis muscle (amplitude $\mu \mathrm{V}$ ) in CTTH patients $47(39,77)$ compared with healthy controls 38 (26, 42). There was no such difference on the left side. The overactivity in trapezius was present bilaterally; the amplitude of EMG (in $\mu \mathrm{V}$ ) of the left trapezius in CTTH patients $84(44,191)$ was significantly higher $(\mathrm{p}=0.042)$ than controls $38(37,86)$. Also, the EMG amplitude (in $\mu \mathrm{V}$ ) of right trapezius in CTTH patients $95(35,207)$ was significantly higher $(\mathrm{p}=0.003)$ than controls $33(20,42)$ (Table 4).

For MVC, the area under curve ( $\mu \mathrm{V}$-s) (Table 5) and amplitude $(\mu \mathrm{V})$ (Table 6) of temporalis and trapezius was not significantly different in CTTH patients when compared to healthy controls. While time to fatigue for MVC was significantly lower in temporalis $(p=0.01)$ and trapezius $(p=0.0007)$ muscles in the CTTH patients versus healthy controls.

\section{DISCUSSION}

Our findings showed an increase in the EMG activity of the trapezius at rest suggesting that muscle overactivity at rest in CTTH may be an important factor contributing to the pain experience although it was statistically significant on the right side. Previously, increased EMG activity was seen in $67 \%$ of CTTH patients with only slight changes during headache [4]. We found a significant difference in the EMG activity during mental activity; it is probable that such an activation is seen during active headache periods. The muscle spasm could both be
Table 1: General characteristics of patients and controls

\begin{tabular}{lll}
\hline Parameter & Healthy controls $\mathbf{n = 3 0}$ & CTTH $\mathbf{n = 3 0}$ \\
\hline $\begin{array}{l}\text { Age (years) } \\
\begin{array}{l}\text { Duration of } \\
\text { headache (years) }\end{array}\end{array}$ & $32.25 \pm 7.5$ & $35.7 \pm 6.56$ \\
$\begin{array}{l}\text { Average pain intensity } \\
\text { (Numerical rating scale) }\end{array}$ & 0 & $6.73 \pm 3.31$ \\
\hline
\end{tabular}

Data expressed as Mean \pm SD. SD: Standard deviation, CTTH: Chronic tension-type headache

Table 2: NFR parameters

\begin{tabular}{llll}
\hline Parameter & $\begin{array}{l}\text { Healthy controls } \\
\mathbf{n}=\mathbf{3 0}\end{array}$ & CTTH $\mathbf{n = 3 0}$ & $\mathbf{p}$ \\
\hline NFR threshold (volts) & $33.75 \pm 10.5$ & $25.50 \pm 8.9$ & 0.009 \\
Latency (ms) & $108.2 \pm 21.6$ & $107.4 \pm 21.3$ & 0.7 \\
Amplitude $(\mu \mathrm{V})$ & $272.5 \pm 120.5$ & $288.4 \pm 166.4$ & 0.9 \\
Duration $(\mathrm{ms})$ & $44.41 \pm 5.06$ & $44.35 \pm 7.20$ & 0.9 \\
\hline
\end{tabular}

Data expressed as Mean \pm SD. NFR: Nociceptive flexion reflex, SD: Standard deviation, CTTH: Chronic tension-type headache, $\mu \mathrm{V}$ : Microvolt

Table 3: EMG amplitude of temporalis and trapezius at rest

\begin{tabular}{llll}
\hline $\begin{array}{l}\text { EMG at } \\
\text { rest-amplitude }(\boldsymbol{\mu V})\end{array}$ & $\begin{array}{l}\text { Healthy controls } \\
\mathbf{n = 3 0}\end{array}$ & CTTH $\mathbf{n = 3 0}$ & $\mathbf{p}$ \\
\hline $\begin{array}{l}\text { Temporalis } \\
\quad \text { Left }\end{array}$ & $43(35,48)$ & $36(22,44)$ & 0.05 \\
$\quad$ Right & $34(25,64)$ & $35(26,43)$ & 0.8 \\
$\begin{array}{l}\text { Trapezius } \\
\text { Left }\end{array}$ & $48(23,71)$ & $65(38,147)$ & 0.07 \\
$\quad$ Right & $27(20,39)$ & $62(32,148)$ & 0.001 \\
\hline
\end{tabular}

Data expressed as median with quartiles. CTTH: Chronic tension-type headache, EMG: Electromyography

Table 4: EMG amplitude of temporalis and trapezius during mental activity

\begin{tabular}{llll}
\hline $\begin{array}{l}\text { EMG during mental } \\
\text { activity-amplitude }(\boldsymbol{\mu V})\end{array}$ & $\begin{array}{l}\text { Healthy } \\
\text { controls } \mathbf{n = 3 0}\end{array}$ & CTTH $\mathbf{n = 3 0}$ & $\mathbf{p}$ \\
\hline $\begin{array}{l}\text { Temporalis } \\
\quad \text { Left }\end{array}$ & $64(35,167)$ & $63(37,101)$ & 0.07 \\
$\quad$ Right & $38(26,42)$ & $47(39,77)$ & 0.0013 \\
$\begin{array}{l}\text { Trapezius } \\
\text { Left }\end{array}$ & $38(37,86)$ & $84(44,191)$ & 0.042 \\
$\quad$ Right & $33(20,42)$ & $95(35,207)$ & 0.003 \\
\hline
\end{tabular}

Data expressed as median with quartiles. CTTH: Chronic tension-type headache, EMG: Electromyography, $\mu$ V: Microvolt

Table 5: EMG AUC of temporalis and trapezius during MVC

\begin{tabular}{llll}
\hline $\begin{array}{l}\text { EMG during } \\
\text { MVC -AUC }(\mu \mathbf{V} \text {-s })\end{array}$ & $\begin{array}{l}\text { Healthy controls } \\
\mathbf{n = 3 0}\end{array}$ & CTTH $\mathbf{n = 3 0}$ & $\mathbf{p}$ \\
\hline Temporalis & & & \\
$\quad$ Left & $1214(771,13776)$ & $1709(906,2726)$ & 0.7 \\
$\quad$ Right & $1639(870,2598)$ & $1658(811,2771)$ & 0.9 \\
Trapezius & & & \\
$\quad$ Left & $3654(1340,5444)$ & $2658(1432,5625)$ & 0.9 \\
$\quad$ Right & $1745(1048,4999)$ & $3006(1152,5952)$ & 0.4 \\
\hline
\end{tabular}

Data expressed as median with quartiles. MVC: Maximum voluntary

contraction, AUC: Area under the curve, EMG: Electromyography, CTTH: Chronic tension-type headache, $\mu \mathrm{V}$-s: Microvolt-second

a cause or effect of the condition and aberrant central pain modulating pathways are a likely cause of hyperalgesia and poor response to therapy. A 12-year-old longitudinal follow-up study demonstrated that the patients who develop CTTH had normal pericranial tenderness, 
Table 6: EMG amplitude of temporalis and trapezius during MVC

\begin{tabular}{llll}
\hline $\begin{array}{l}\text { EMG during } \\
\text { MVC - amplitude } \\
(\boldsymbol{\mu V})\end{array}$ & $\begin{array}{l}\text { Healthy } \\
\text { controls } \mathbf{n}=\mathbf{3 0}\end{array}$ & CTTH $\mathbf{n = 3 0}$ & $\mathbf{p}$ \\
\hline $\begin{array}{l}\text { Temporalis } \\
\quad \text { Left }\end{array}$ & $822(592,1186)$ & $797(601,1395)$ & 0.7 \\
$\quad$ Right & $647(456,948)$ & $867(595,1499)$ & 0.17 \\
$\begin{array}{l}\text { Trapezius } \\
\text { Left }\end{array}$ & $1946(565,2557)$ & $2012(593,2709)$ & 0.9 \\
$\quad$ Right & $1133(476,2512)$ & $1718(921,3427)$ & 0.3 \\
\hline
\end{tabular}

Data expressed as median with quartiles. MVC: Maximum voluntary

contraction, EMG: Electromyography, CTTH: Chronic tension-type headache, $\mu \mathrm{V}$ : Microvolt

Table 7: Time to fatigue of temporalis and trapezius during MVC

\begin{tabular}{llll}
\hline $\begin{array}{l}\text { Time to } \\
\text { fatigue }(\mathbf{s})\end{array}$ & $\begin{array}{l}\text { Healthy controls } \\
\mathbf{n = 3 0}\end{array}$ & $\begin{array}{l}\mathbf{C T T H} \\
\mathbf{n = 3 0}\end{array}$ & $\mathbf{p}$ \\
\hline Temporalis & $30(25,43)$ & $21(16,28)$ & 0.01 \\
Trapezius & $45(38,66)$ & $29(23,38)$ & 0.0007 \\
\hline
\end{tabular}

Data expressed as median with quartiles. CTTH: Chronic tension-type headache, MVC: Maximum voluntary contraction, s: Second

to begin with, suggesting that it is a consequence rather than cause [11]. There are many studies showing decreased pressure pain thresholds [12], while others have shown an inverse relation between pericranial tenderness and pain threshold [13]. The level of activity assessed by EMG in the pericranial muscles is on the higher side in patients with CTTH than in healthy controls. The absolute root means square frequency and relative percentage values at the initial and final period during sustained isometric contraction decreased significantly in the CTTH group. We are reporting an increased fatigability of the muscles during MVC. Some have studied this as outside of headache and found that muscle tenderness and EMG activity levels were significantly increased compared to values in controls subjects. It is concluded that one of the primary sources of pain in tension-type headache may be a local and reversible sensitization of nociceptors in the pericranial muscle, mechanical strain [14], and muscle ischemia [15]. Previous reports showed altered blood flow in muscle was caused by disturbed regulation of peripheral mechanisms because of central sensitization or generalized hyperalgesia [16]. Although the activity was not significantly different, it is probable that such an effect may be there during active headache episodes. A different muscle firing pattern or some muscle modifications in patients with CTTH may reflect the reorganization of the motor control strategy $[17,18]$. There are detectable distinct muscular responses in chronic headache sufferers. This finding could be due to adaptation to muscle underuse or sustained contraction, leading to impaired recruitment, and muscle fiber-type conversion with dominant type I fibers in CTTH [17].

The results of the present study indicate that in CTTH patients there is a decrease in the NFR thresholds with no significant change in the other characteristics such as latency, amplitude, and duration. NFR being a spinally mediated response subjected to supraspinal and limbic modulation and has been widely reported by pain researchers. NFR or RIII is a polysynaptic withdrawal reflex originally discovered by Sherrington in 1910 in decerebrate animals where he saw that electrical stimulation causes flexion of hip knee and ankle. It is different from the nocuous flexion reflex as the flexion phase is not maintained and flexion at knee and ankle ceases somewhat earlier than does the flexion at hip, whereas in the nociceptive reflex flexion at all three joints is maintained. Also, flexion is greater and is succeeded by extension only after the stimulus is withdrawn, whereas in the step-reflex it is succeeded by extension [19]. In humans, the afferents were carried by A delta and C fibers as demonstrated in paretic patients [20]. In 1960, when Kugelberg et al. electrically stimulated various areas in the foot and gluteal region and recorded response by needle EMG the threshold of the nociceptive reflexes varied considerably in different regions according to its biological function although it could be elicited almost anywhere [21]. Stimulation of the sural nerve (through the skin) elicits two different reflex responses in the biceps femoris: The first RII is of short latency, low threshold and corresponds to tactile reflex $A \beta$ fibers. The second (RIII) is of longer latency and a higher threshold and corresponds to a nociceptive reflex. The threshold of RIII was found to be the threshold of a pain sensation. Stimulation of the skin elicits only a late nociceptive (RIII) response in the biceps femoris. This was used as an index of efficacy of analgesic drugs, stress, mental activation, and homotopic noxious stimulation [22-25]. In an experimental situation, the nociceptive withdrawal reflex can be elicited by heat [26] or electrical stimulations. Electrical stimulation may either be of a pure sensory nerve, for example, the sural nerve [23], or cutaneous stimulation (stimulation of distal cutaneous afferents) on foot [27]. The NFR threshold correlates well with the subjective experience of pain in patients with sciatica [28], fibromyalgia [29], after functional neurosurgery [30]. and in demonstrating the efficacy of lidocaine in painful diabetic neuropathy [31]. The NFR has been investigated in patients with different types of chronic headaches [32]. A good correlation between the reflex and pain was demonstrated in patients with a migraine, but studies in patients with a tension-type headache and hemicrania continua have yielded conflicting data [33,34].

\section{CONCLUSION}

The results reflect a predominant role of central factors in the pathogenesis of CTTH and the peripheral muscle overactivity being a contributory factor. EMG activity of temporalis and trapezius muscle also shows an overactivity in our patients especially during the mental task and increased fatigability during MVC. However, some studies fail to show an increase in the EMG activity; this variation is largely due to different techniques and muscle groups. Therefore, we conclude that muscle overactivity could be a contributing factor toward the pain experience in CTTH. The spinally mediated NFR showed a significant difference in headache-free controls and pain patients. NFR is considered as a reliable and objective tool in pain assessment and is also affected by central pain modulating matrix. We observed a decreased NFR threshold as has been previously reported in CTTH suggesting a hyperalgesic state due to central factors.

\section{AUTHOR'S CONTRIBUTION}

Bhawna Mattoo: Design of the work; Data Acquisition and Analysis, interpretation of data, final approval. Suman Tanwar: Data acquisition and analysis, final approval. Rohit Bhatia: Patient recruitment, interpretation of data, final approval. Manjari Tripathi: Patient recruitment, interpretation of data, final approval. Renu Bhatia: Design of the work, interpretation, and final approval.

\section{CONFLICTS OF INTEREST}

The authors have no conflicts of interest concerning the work reported in this paper.

\section{REFERENCES}

1. Thakur S, Srivastava N. An update on neuropathic pain models. Int J Pharm Pharm Sci 2016;8:11-6.

2. Jena M, Mishra S, Pradhan S, Jena S, Mishra SS. Chronic pain, its management and psychological issues: A review. Asian J Pharm Clin Res 2015;8:42-7.

3. Saharan V, Pandey M. A study of prevalance of self medication practice among people of Mumbai. Int J Pharm Pharm Sci 2015;7:253-6.

4. Jensen R, Bendtsen L, Olesen J. Muscular factors are of importance in tension-type headache. Headache 1998;38:10-7.

5. Rhudy JL, France CR. Defining the nociceptive flexion reflex (NFR) threshold in human participants: A comparison of different scoring criteria. Pain 2007;128(3):244-253.

6. Headache Classification Committee of the International Headache Society (IHS). The International Classification of Headache Disorders, 3rd edition (beta version). Cephalalgia 2013;33:629-808.

7. von Dincklage F, Hackbarth M, Schneider M, Baars JH, Rehberg B. 
Introduction of a continual RIII reflex threshold tracking algorithm. Brain Res 2009;1260:24-9.

8. Jurth C, Rehberg B, von Dincklage F. Reliability of subjective pain ratings and nociceptive flexion reflex responses as measures of conditioned pain modulation. Pain Res Manag 2014;19:93-6.

9. Cram J. Cram's Introduction to Surface Electromyography. $2^{\text {nd }}$ ed. Nevada City, CA: Jones \&Bartlett Learning; 2010.

10. Bhatia R, Dureja GP, Tripathi M, Bhattacharjee M, Bijlani RL, Mathur R. Role of temporalis muscle overactivity in chronic tensiontype headache: Effect of yoga based management. Indian J Physiol Pharmacol 2007;51:333-44.

11. Buchgreitz L, Lyngberg A, Bendtsen L, Jensen R. Increased prevalence of tension-type headache over a 12-year period is related to increased pain sensitivity. A population study. Cephalalgia 2007;27:145-52

12. Patra R, Mohanty P, Gautam AP. Effectiveness of $\mathrm{c} 1-\mathrm{c} 2$ sustained natural apophyseal glide combined with dry needling on pressure point threshold and headache disability in cervicogenic headache. Asian J Pharm Clin Res 2018;11:171-4.

13. Schoenen J, Gerard P, De Pasqua V, Juprelle M. EMG activity in pericranial musclesduring postural variation and mental activity in healthy volunteers and patients with chronic tension-type headache. Headache 1991;31:321-4.

14. Bendtsen L, Ashina S, Moore A, Steiner TJ. Muscles and their role in episodic tension-type headache: Implications for treatment. Eur J Pain 2016;20:166-75.

15. Ashina M, Stallknecht B, Bendtsen L, Pedersen JF, Galbo H, Dalgaard P, et al. In vivo evidence of altered skeletal muscle blood flow in chronic tension-type headache. Brain J Neurol 2002;125:320-6.

16. Ashina S, Bendtsen L, Ashina M, Magerl W, Jensen R. Generalized hyperalgesia in patients with chronic tension-type headache. Cephalalgia 2006;26:940-8.

17. Biyouki F, Laimi K, Rahati S, Boostani R, Shoeibi A. Morphology of muscular function in chronic tension-type headache: A pilot study. Acta Neurol Belg 2016;116:317-24.

18. Sohn JH, Choi HC, Jun AY. Differential patterns of muscle modification in women with episodic and chronic tension-type headache revealed using surface electromyographic analysis. J Electromyogr Kinesiol 2013;23:110-7.

19. Sherrington CS. Flexion-reflex of the limb, crossed extension-reflex, and reflex stepping and standing. J Physiol 1910;40:28-121.
20. Kugelberg E. Demonstration of $\mathrm{A}$ and $\mathrm{C}$ fibre components in the Babinski plantar response and the pathological flexion reflex. Brain 1948;71:304-19.

21. Kugelberg E, Eklund K, Grimby L. An electromyographic study of the nociceptive reflexes of the lower limb. Mechanism of the plantar responses. Brain 1960;83:394-410.

22. Sandrini G, Alfonsi E, Bono G, Facchinetti F, Montalbetti L, Nappi G. Circadian variations of human flexion reflex. Pain 1986;25:403-10.

23. Willer JC, Bathien N. Pharmacological modulations on the nociceptive flexion reflex in man. Pain 1977;3:111-9.

24. Willer JC. Studies on pain. Effects of morphine on a spinal nociceptive flexion reflex and related pain sensation in man. Brain Res 1985;331:105-14.

25. Willer JC, Boureau F, Albe-Fessard D. Supraspinal influences on nociceptive flexion reflex and pain sensation in man. Brain Res 1979;179:61-8.

26. Campbell IG, Carstens E, Watkins LR. Comparison of human pain sensation and flexion withdrawal evoked by noxious radiant heat. Pain 1991;45:259-68.

27. Willer JC. Comparative study of perceived pain and nociceptive flexion reflex in man. Pain 1977;3:69-80.

28. Willer JC, Barranquero A, Kahn MF, Salliere D. Pain in sciatica depresses lower limb nociceptive reflexes to sural nerve stimulation. J Neurol Neurosurg Psychiatry 1987;50:1-5.

29. Guieu R, Serratrice G, Pouget J. Counter irritation test in primary fibromyalgia. Clin Rheumatol 1994;13:605-10.

30. García-Larrea L, Sindou M, Mauguière F. Clinical use of nociceptive flexion reflex recording in the evaluation of functional neurosurgical procedures. Acta Neurochir Suppl (Wien) 1989;46:53-7.

31. Bach FW, Jensen TS, Kastrup J, Stigsby B, Dejgård A. The effect of intravenous lidocaine on nociceptive processing in diabetic neuropathy. Pain 1990;40:29-34.

32. Sandrini G, Arrigo A, Bono G, Nappi G. The nociceptive flexion reflex as a tool for exploring pain control systems in headache and other pain syndromes. Cephalalgia 1993;13:21-7.

33. Rhudy JL, France CR. Reliability and validity of a brief method to assess nociceptive flexion reflex (NFR) threshold. J Pain 2011;12:782-91.

34. Langemark M, Bach FW, Jensen TS, Olesen J. Decreased nociceptive flexion reflex threshold in chronic tension-type headache. Arch Neurol $1993 ; 50: 1061-4$ 